TITLE:

\title{
Vocal Shimmer in Sustained Phonation of Normal and Pathologic Voice.
}

\section{$\operatorname{AUTHOR}(\mathrm{S}):$}

Kitajima, Kazutomo; Gould, Wilbur J.

\section{CITATION:}

Kitajima, Kazutomo ... [et al]. Vocal Shimmer in Sustained Phonation of Normal and Pathologic Voice.. 音声科学研究 1976, 10: 23-27

ISSUE DATE:

1976

URL:

http://hdl.handle.net/2433/52577

RIGHT: 


\title{
Vocal Shimmer in Sustained Phonation of Normal and Pathologic Voice
}

\author{
Kazutomo KITAJIMA \\ and Wilbur J. GOULD
}

In author's previous article ${ }^{1}$, the pitch perturbation of normal and pathologic voice was analyzed. In this study, the minute amplitude variation of the sustained phonation was analyzed aiming to formulate acoustic criteria that might be useful in differentiating the pathologic voice from the normal one.

\section{Subject}

The subject were 32 men and 13 women with no laryngeal or pulmonary disorders, who served as normals or controls, and 14 men and 6 women who had vocal cord polyps of various sizes and locations. The age distribution was 17 to 74 years for the normals, 27 to 68 for those with vocal cord polyps.

\section{METHOD}

1) Recording of voice: A magnetic recording of each subject, using a microphone (Electrovoice 666) and a taperecorder (Sony TC-650, at $19 \mathrm{~cm} . / \mathrm{sec}$.) was done in a sound treated booth. The microphone to mouth distance was approximately $20 \mathrm{~cm}$. A stable portion of the sustained vowel $/ \mathrm{a} /$, uttered at a comfortable pitch and intensity, was used for analysis.

2) Measurement: A $360 \mathrm{msec}$. duration of the voice signal was digitized after filtering through a $1500 \mathrm{~Hz}$ low pass filter (Krohn-Hite 3500). A $360 \mathrm{msec}$. was the maximum duration of a signal that the computer could process. The signal was sampled at 20,000 samples per second and quantitized into nine bits. Measurements were made upon this digitized signal.

To measure the amplitude, a display scope was programmed to show the voice signal on it (see Fig. 1). Due to the capacity of the scope, approximately 25 msec. duration of the signal could be displayed at once. The procedure used to measure the amplitude associated with each period is illustrated in Fig. 2. Point $P_{i}$ indictes the amplitude peak of each cycle, while point $b$ or $c$ indicate lowermost point of the cycle. Point $\mathrm{a}$ is determined by the intersection of the perpendicular to $P_{i}$ with the line $b-c$. The distance $P_{i}-a$, that is $A_{i}$ was taken to be the amplitude of each cycle. The distance $P_{i}-P_{1+1}$ was defined as pitch

Kazutomo KITAJIMA (北嶋和智): Department of Otolaryngology, Faculty of Medicine, Kyoto University. Director: Prof. M. Hinoki Wilbur J. GOULD: Vocal Dynamics Laboratory, 


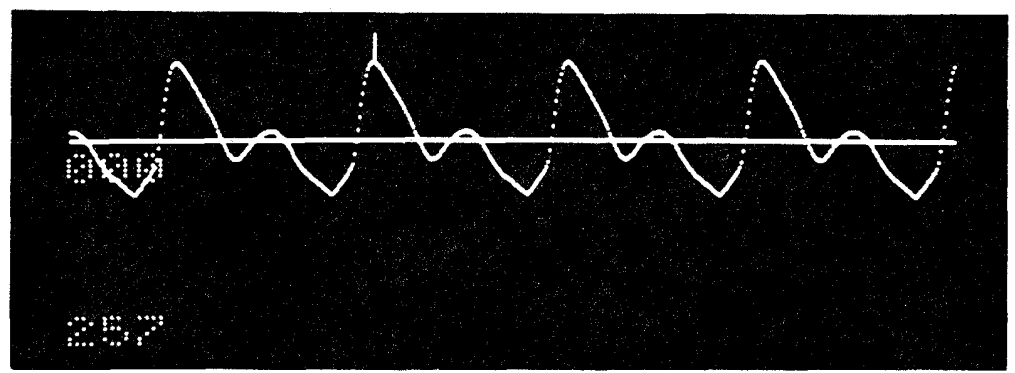

Fig. 1. A section of the sound signal as displayed on the scope.

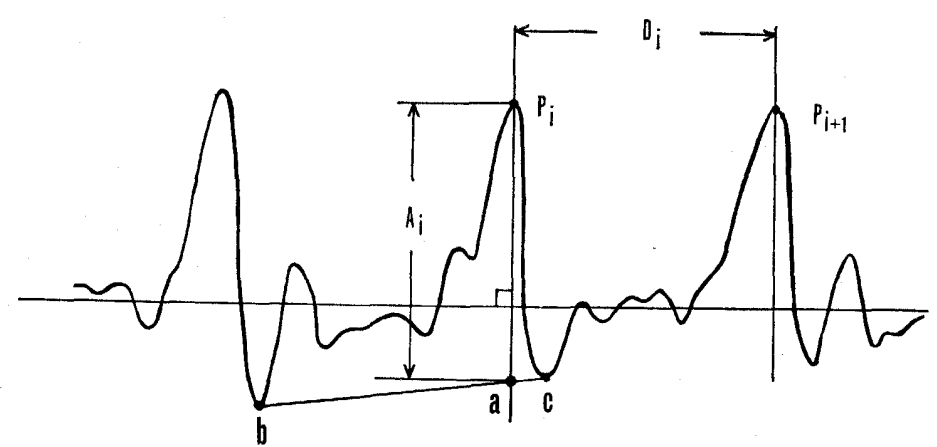

Fig. 2. Definition of amplitude. Amplitude $A_{i}$ is defined as a vertical distance between point $P_{i}$ and point $a$. Point $a$ is where the perpendicular line form $\mathrm{P}_{\mathbf{i}}$ intersects line $\mathrm{b}-\mathrm{c}$. Point $\mathrm{b}$ or $\mathrm{c}$ indicate lowermost point of the cycle. The horizontal distance between $P_{1}$ and $P_{i+1}$ is defined as pitch period.

period $\mathrm{D}_{1}$. In practice, $\mathrm{P}_{1}, \mathrm{~b}$ and $\mathrm{c}$ were positioned using a cursor which was displayed on the scope. The co-ordinates of these points were memorized by pressing a switch of the control board. The amplitude $A_{i}$ was then calculated automatically by the computer on the basis of these three points. After the procedures on the first section were finished, consecutive section of the signal was displayed for repeating the same procedures.

Vocal shimmer was expressed as the mean amplitude difference between consecutive cycles in $\mathrm{dB}$, using the following:

$$
\text { vocal shimmer }=\frac{\sum_{i=1}^{N} 20 x\left|\log \frac{A_{i+1}}{A_{i}}\right|}{N}
$$

Where: $N=$ the number of pitch period measured, $A_{i}=$ the amplitude of period $i$, $A_{i+1}=$ the amplitude for the period following $A_{i}$.

\section{RESULT}

1) Distribution of normal controls

The values of vocal shimmer in 45 normal subjects ranged from $0.04 \mathrm{~dB}$ to $0.21 \mathrm{~dB}$. The distribution is shown in Fig. 3. Vocal shimmer expressed in $\mathrm{dB}$ is on the absissa; number of subjects on the ordinate. As can be seen, 13 


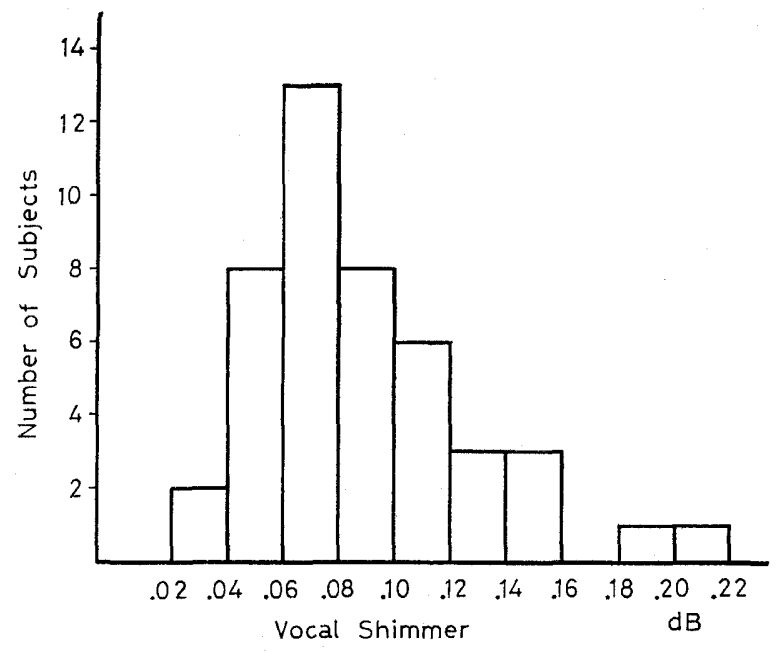

Fig. 3. Histogram of vocal shimmer in normal subjects.

subjects out of 45 locate between $0.06 \mathrm{~dB}$ and $0.08 \mathrm{~dB}$. 29 Subjects have the values between $0.04 \mathrm{~dB}$ and $0.10 \mathrm{~dB}$. The upper limit of the critical region calculated from these data was $0.19 \mathrm{~dB}$ at $5 \%$ level of significance.

2) The values of the laryngeal polyps

The result of 20 subjects is listed in Table 1. The asterisks in this table

Table 1. Vocal shimmer in $\mathrm{dB}$. pre-operative.

\begin{tabular}{c|l}
\hline Subject number & $\mathrm{dB}$. \\
\hline 1 & 0.14 \\
2 & $1.42^{*}$ \\
3 & 0.19 \\
4 & $0.57^{*}$ \\
5 & $0.39 *$ \\
6 & $0.53^{*}$ \\
7 & $0.28^{*}$ \\
8 & $0.32^{*}$ \\
9 & $0.24^{*}$ \\
10 & $0.55^{*}$ \\
11 & $0.35^{*}$ \\
12 & $0.30^{*}$ \\
13 & 0.14 \\
14 & $0.25^{*}$ \\
15 & $0.30 *$ \\
16 & 0.09 \\
17 & $0.24 *$ \\
18 & 0.18 \\
19 & 0.08 \\
20 & $0.21 *$ \\
\hline
\end{tabular}

Table 2. Vocal shimmer in dB. post-operative

\begin{tabular}{c|l}
\hline Subject number & $\mathrm{dB}$. \\
\hline 1 & 0.08 \\
2 & 0.17 \\
3 & 0.14 \\
4 & $0.24^{*}$ \\
5 & $0.38^{*}$ \\
6 & $0.32^{*}$ \\
7 & $0.30^{*}$ \\
8 & $0.32^{*}$ \\
9 & 0.16 \\
10 & $0.33^{*}$ \\
11 & $0.28^{*}$ \\
12 & $0.32^{*}$ \\
13 & 0.13 \\
15 & $0.24^{*}$ \\
15 & 0.13 \\
16 & 0.06 \\
17 & 0.09 \\
18 & 0.06 \\
19 & 0.07 \\
20 & 0.18 \\
\hline
\end{tabular}


indicate that the values marked are exceeding the normal region. Fourteen subjects have the abnormal values. The subjects analyzed in this study have the polyps of various sizes and locations. Therefore in the case of small polyp, it is not unexpected that the measured value marges with the normal region.

In Table 2, post-operative values of the laryngeal polyps are listed. Nine subjects still have the abnormal values. These pre- and post-operative results are illustrated in Fig. 4. On the left of this figure, the pre-operative values

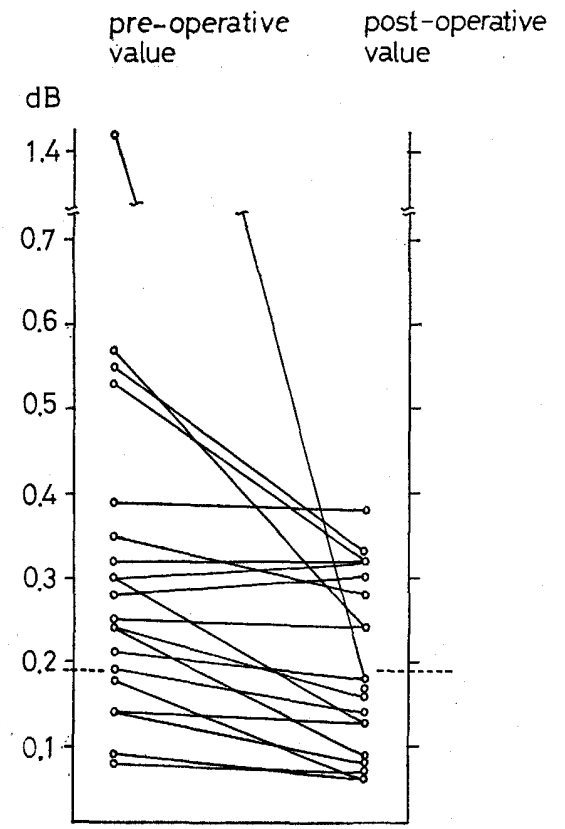

Fig. 4. Vocal shimmer of the laryngeal polyps. Pre- and post-oper ative values are connected by the straight line for each subject.

and on the right side, the post-operative ones are plotted. For each subject these pre and post-operative values are connected by the straight line. The horizontal dotted line indicate the upper limit of the normals $(0.19 \mathrm{~dB})$. As is noticed, some show the marked decrease after the operation, and some do not. Nine subject still have the abnormal values after the operation, and among these subjects- five ones do not show much difference between pre and post-operation. The effect of the operation is thought to depend upon the size and location of the polyp. Therefore, considering the various size and location of the polyps analyzed, it is not unexpected that some cases did not show much difference.

Although there is some overlap between the normals and the polyps, the vocal shimmer defined and measured here may nevertheless be a useful parameter for the differenciation of these two groups and can be used as a tool for objective evaluation of the hoarseness.

As has been known in our clinical practice, the voice of the laryngeal polyp 
has the auditory impression of roughness, rather than breathiness. It could be suggested by the Fig. 4 that the vocal shimmer is closely related with the acoustic impression of the laryngeal polyp.

\section{REFERENCES}

1. Kitajima, K., Tanabe, M. and Isshiki, N.: Pitch Perturbation in Normal and Pathologic Voice. Studia Phonologica, 9: 25-32, 1975.

2. Lieberman, P.: Perturbation in Vocal Pitch. J. Acoust. Soc. Am., 33: 597-603, 1961.

3. Lieberman, P.: Some Acoustic Measures of the Fundamental Periodicity of Normal and Pathologic Larynges. J. Acoust. Soc. Am., 35: 344-353, 1963.

4. Smith, W. R. and Lieberman, P.: Computer Diagnosis of Laryngeal Lesion. Comput. Biomed. Res., 2: 291-303, 1969.

5. Hecker, M. H. L. and Kreul, E. J.: Description of the Speech of Patients with Cancer of the Vocal Folds. Part 1: Measurement of Fundamental Frequency. J. Acoust. Soc. Am., 49: 1275-1282, 1971.

6. Hollien, H., Michel, J. and Doherty, E. T.: A Method for Analyzing Vocal Jitter in Sustained Phonation. J. Phonetics, 1: 85-91, 1973.

7. Koike, Y.: Vowel Amplitude Modulation in Patients with Laryngeal Diseases. J. Acoust. Soc. Am., 45: 839-844, 1969.

8. Crystal, T.H. and Jackson, C. L.: Extracting and Processing Vocal Pitch for Laryngeal Disorder Detection. J. Acoust. Soc. Am., 48: 118, 1970.

9. Wendahl, R. W.: Laryngeal Analog Synthesis of Jitter and Shimmer. Auditory Parameters of Harshness. Folia phoniat., 18: 98-108, 1966.

10. Goleman, R. F.: Effect of Waveform Changes upon Roughness Perception. Folia phoniat,, 23: 314-322, 1971.

11. Koike, Y.: Application of Some Acoustic Measures for the Evaluation of Laryngeal Dysfunction. Studia Phonologica, 7: 17-23, 1973.

(Aug. 31, 1976, received) 